\title{
ESTUDO DE MOLÉCULAS TRI- E TETRA-ATÔMICAS E ÁTOMOS CONFINADOS
}

\author{
Henrique Costa Lima1; Vladimir Ramos Vitorino de Assis ${ }^{2}$ \\ 1. Bolsista PIBIC/CNPq, Graduando em do Engenharia Civil, Universidade Estadual de Feira de Santana, e-mail: \\ henrique_costa11@hotmail.com \\ 2. Orientador, Departamento de Física, Universidade Estadual de Feira de Santana, e-mail: vladimir@uefs.br
}

PALAVRAS-CHAVE: Baterias; Poluição; Microcristais.

\section{INTRODUÇÃO}

O trabalho realizado teve como objetivo estudar a reação química de oxirredução:

$$
\mathrm{Pb}(\mathrm{s})+\mathrm{PbO} 2(\mathrm{~s})+2 \mathrm{H} 2 \mathrm{SO} 4(\mathrm{aq}) \rightarrow 2 \mathrm{PbSO} 4(\mathrm{~s})+2 \mathrm{H} 2 \mathrm{O}(\mathrm{l})
$$

Usada em baterias de chumbo ácido, possui as seguintes reações nos eletrodos:

$$
\begin{aligned}
& \text { Polo negativo, } \mathrm{Pb}(\mathrm{s})+\mathrm{H} 2 \mathrm{SO} 4(\mathrm{aq}) \rightarrow \mathrm{PbSO} 4(\mathrm{~s})+2 \mathrm{H}+(\mathrm{aq})+2 \mathrm{e}- \\
& \text { Polo positivo, } \mathrm{PbO} 2(\mathrm{~s})+\mathrm{H} 2 \mathrm{SO} 4(\mathrm{aq})+2 \mathrm{H}+(\mathrm{aq})+2 \mathrm{e}-\rightarrow \mathrm{PbSO} 4(\mathrm{~s})+2 \mathrm{H} 2 \mathrm{O}(\mathrm{l})
\end{aligned}
$$

Apesar dos esforços extensivos e contínuos para desenvolver novos fontes de luz e energia eletroquímica secundária de baixo custo, como a bateria de chumbo ácido ainda é confiável e barata em uma base de custo por watt, ela continua a ser amplamente utilizada até hoje, principalmente por automóveis, cadeiras de rodas motorizadas, equipamentos hospitalares, luzes de emergência e etc. Desta forma, devido a sua importância nos aspectos econômicos e ambientais ligados a produção, comercialização e eliminação se torna clara a utilidade de um estudo que visa prolongar a vida útil das baterias por meio de recargas controladas que minimizam a formação de cristais. Porém, devido à complexidade dos processos envolvidos no funcionamento do sistema, tem sido difícil encontrar um modelo único que descreva adequadamente o seu comportamento, uma das formas de resolver esse problema é aprofundar o conhecimento nos processos envolvidos nas reações da bateria. Então, fazendo um estudo de caso de uma bateria de chumbo ácido pretende-se entender melhor como os cristais de sulfato de chumbo são formados e como pode-se minimiza-los por meio de um carregamento adequado.

\section{MATERIAL E MÉTODOS OU METODOLOGIA}

Para a construção da bateria inicialmente foi produzido uma cópia do eletrodo com o auxílio de uma impressora 3D, que serviu de base para fazer os moldes em gesso. Em seguida após colocar as pequenas barras chumbo no molde de gesso, ele foi derretido com o auxílio de um maçarico, fazendo ele adquirir a forma do eletrodo presente no gesso.

O eletrólito utilizado foi o ácido sulfúrico a 35\%, que foi adicionado ao balão de fundo redondo com três bocas e posteriormente fechado com tampas de silicone adequadas. A interface utilizada que permitiu a transmissão de dados e o carregamento da bateria foi o Arduino. A garra de condensador foi utilizada para fixar o balão de 
fundo redondo com três bocas no suporte universal, o qual permitiu a estabilidade do sistema. A figura 1 representa a lista de materiais utilizadas.

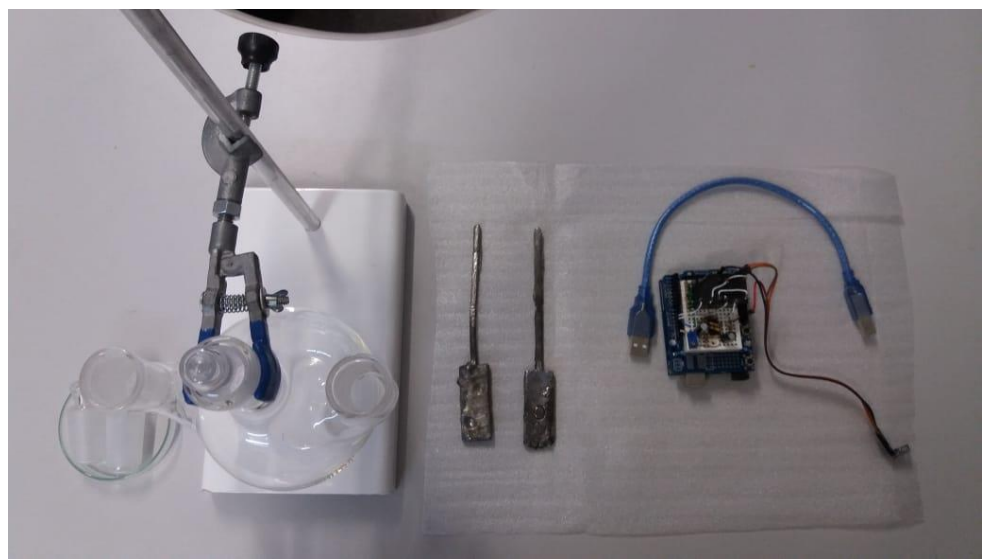

Figura 1: lista de materiais utilizado.

\section{RESULTADOS E/OU DISCUSSÃO}

Após a oxidação do eletrodo positivo da bateria ter sido feita, notou-se que a auto descarga (descarga com corrente nula) ocorreu de forma espontânea em 7 horas chegando em 1,75v, que é a tensão de fim de descarga recomendada para a bateria de chumbo ácido selada. Percebeu-se então que por esta bateria apresentar a pressão interna baixa, a eletrólise da água ocorre e por isso a auto descarga é potencializada, resultando em dois momentos em que a bateria mantém sua tensão mais estável: a tensão nominal da bateria e a tensão de eletrólise da água. Para entender qual o melhor método para carregar esta bateria e analisar como o carregamento pode influenciar na formação dos cristais de sulfato, adotou-se dois métodos de carregamento um com corrente constante e outro com corrente pulsada.

Os primeiros testes foram feitos com corrente constante, o qual obteve-se uma menor auto descarga aplicando-se um tempo de 4 horas no estágio 9 do programa do carregamento da bateria. A figura abaixo demonstra as curvas da auto descarga da bateria para o carregamento com 9,5 e 4 horas no estágio 9.

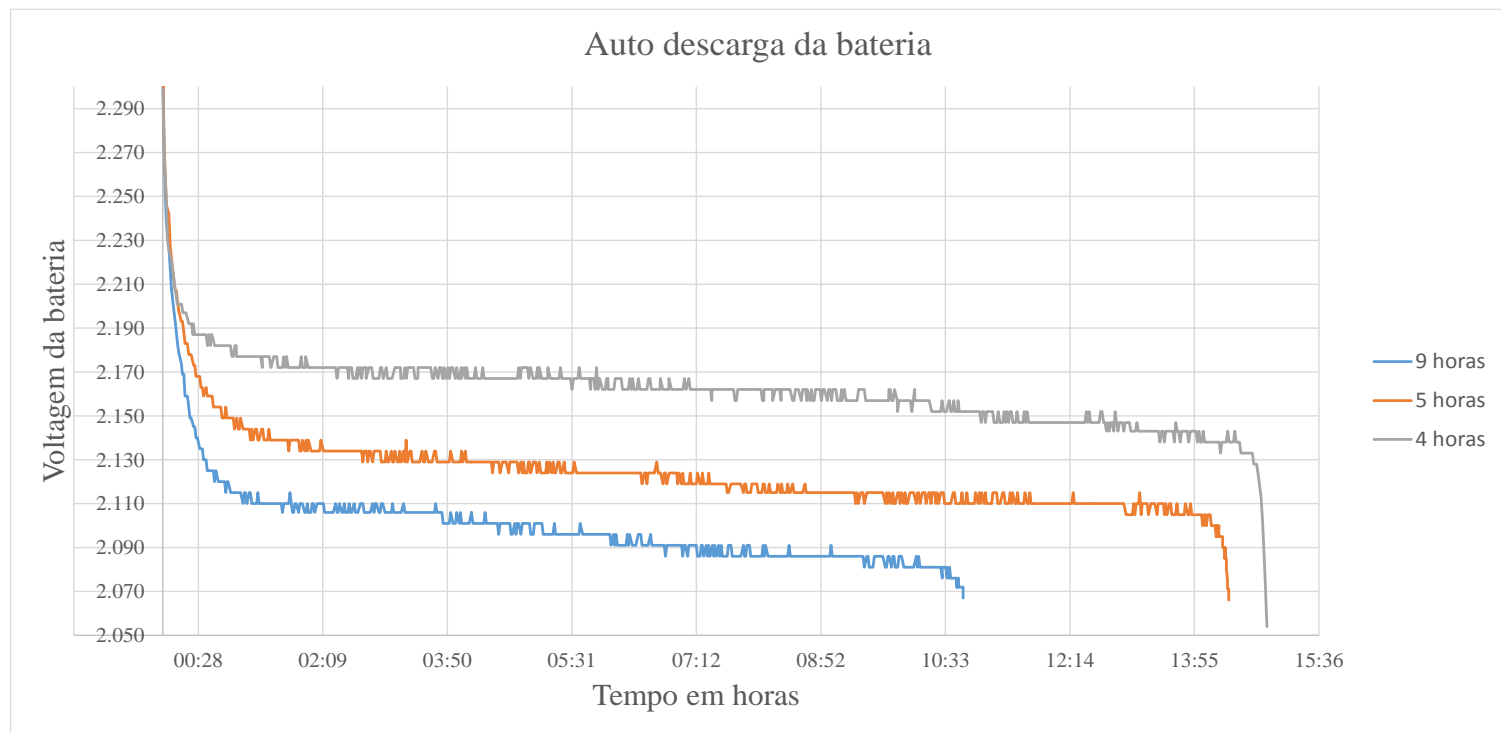

Figura 2: Comparação da auto descarga de carregamentos por corrente constante. 
Para localizar os possíveis cristais foi utilizado o conceito de refração da luz, no qual após a luz atravessar um cristal, ela se decompõe em infinitos raios de luzes monocromáticas, conhecido como arco-íris, permitindo assim identificar possíveis cristais. A escala de todas as fotos são 1/70.

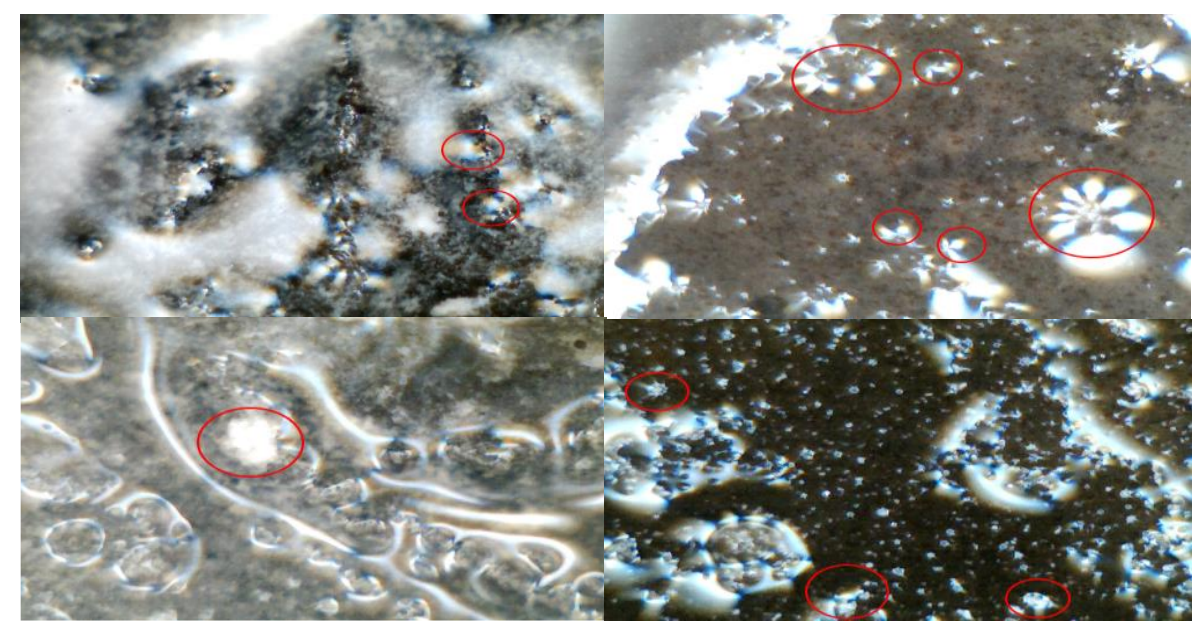

Figura 3: Possíveis cristais de sulfato de chumbo, a esquerda o eletrodo negativo e direita positivo. Em cima os eletrodos parcialmente descarregados, em baixo totalmente descarregados.

Por motivos semelhantes ao da corrente pulsada, foram testados pulsos de diferentes tempos, assim como foram testados tempos diferentes para o estágio 9. Porém, a única constatação que se obteve com esse tipo de carregamento é que ele é prejudicial a bateria, não carregando a bateria e por conta disso danificando ela por conta de cargas incompletas. Após a conclusão da avalição do carregamento pulsado 1.0 , testou-se o carregamento com corrente constante novamente, junto com um novo método de carregamento, que combina o carregamento pulsado com o constante. Em seguida foi feita uma nova sessão de fotos com o objetivo de identificar a formação de cristais.

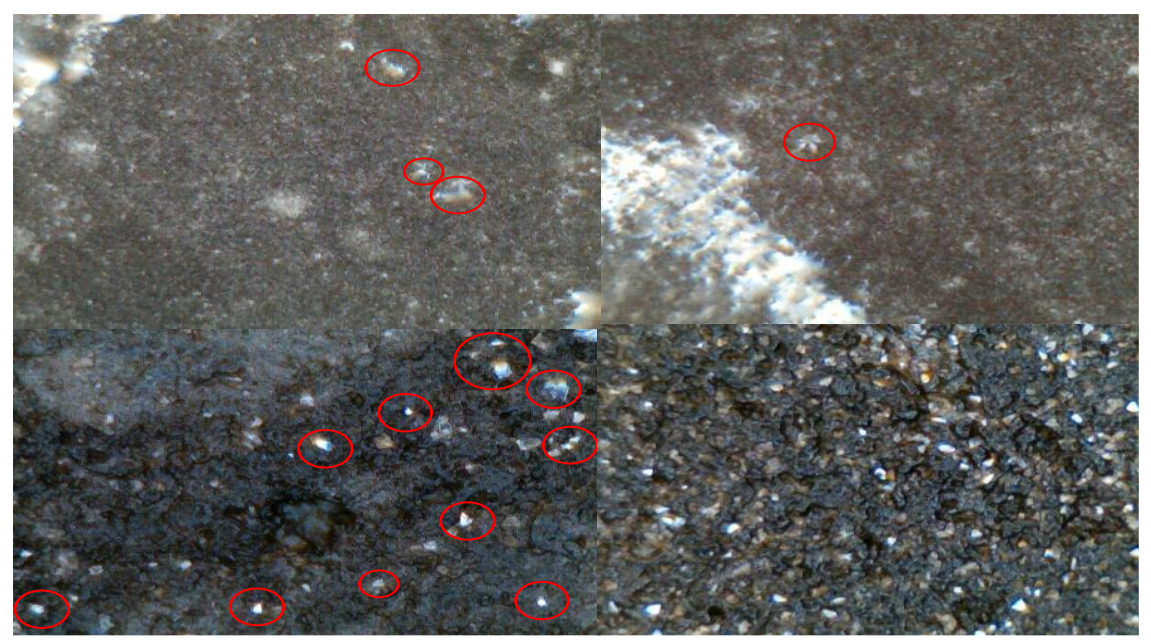

Figura 4: Cristais de sulfato de chumbo nos eletrodos parcialmente descarregados. Em cima, o eletrodo negativo, em baixo, a esquerda, a parte central do eletrodo positivo, a direita, a borda do eletrodo positivo. 


\section{CONSIDERAÇÕES FINAIS}

Os principais objetivos deste trabalho foram, estudar a formação dos cristais de sulfato de chumbo e entender como o carregamento pode influenciar no crescimento de cristais, por meio de um estudo de caso, sendo portanto, os resultados obtidos neste trabalho exclusivos para esta bateria, porém, com resultados importantes para o melhor entendimento das reações químicas que ocorrem na bateria. Os objetivos foram avaliados pela auto descarga e pelas fotos dos cristais, não podendo ser feito uma avalição mais complexa das medidas de cristalização devido ao tempo gasto com outros processos que este trabalho envolveu. Para obter o crescimento destes cristais, resolveuse aplicar na bateria os processos que mais desgastam ela, como descargas profundas com recargas incompletas, deixar a bateria com carga incompleta por um tempo prolongado e sobrecarga. A grande maioria destes processos prejudiciais foi aplicado quando se estava aprendendo sobre essa bateria, danificando consideravelmente ela antes de realmente testa-la. Mas, após 15 ciclos de recargas completas com corrente constante, verificou-se a pequena formação de cristais durante o descarregamento, evidenciando que mesmo após ser prejudicada seriamente, após recarrega-la de um jeito menos prejudicial algumas vezes, o tempo para a bateria se descarregar completamente com corrente nula foi aumentando gradualmente, o que pode significar que ela foi capaz de quebrar alguns cristais, sendo portanto, este um método de carregar, efetivo para recuperar parte de sua vida. Na segunda sessão de fotos percebeu-se que entre os processos que podem danificar a bateria, como cargas incompletas e sobrecargas, a descarga profunda é a que mais afeta a vida útil. Isso é devido ao fato dos cristais que se formam durante o processo de descarga profunda serem maiores e mais difíceis de quebrar durante o processo de carga, acumulando os cristais e formando novos a cada ciclo de descarga.

No decorrer do trabalho, foram observados assuntos que poderiam ser aprofundados para um completo entendimento das reações que ocorrem na bateria de chumbo ácido, como os métodos de carregamento, o pulso na carga e o pulso na descarga. Sendo que o pulso na carga já estava sendo testado de outra forma, na qual o este método de carregamento, chamado carregamento pulsado 2.0 obteve o maior tempo de auto descarga. Porém, como os resultados foram preliminares, não se pode afirmar com certeza que este foi o melhor método encontrado sendo necessário mais testes para uma conclusão definitiva.

\section{REFERÊNCIAS}

FERRAZ, F. F. Análise Das Políticas Públicas Para a Inclusão Do Automóvel Elétrico No Brasil. 2015. Dissertação (Mestrado em Ciências) - Programa de Pós-Graduação em energia, Universidade de São Paulo, São Paulo.

LEAD BASED BATTERIES. How does the Lead Acid Battery Work?. Disponível em: <http://batteryuniversity.com/learn/article/lead_based_batteries> Acesso em: $16 \mathrm{de}$ março de 2018.

ROWE, J. Lead-acid Battery Zapper. Silicon Chip, Austrália, v. 18, no. 7, p. 38, jul. 2005.

STA ELETRONICA (2018). Como Carregar Bateria Selada De Chumbo Ácido. Disponível em: <http://www.sta-eletronica.com.br/artigos/como-carregar-uma-bateriaselada-de-chumbo-acido> Acesso em: 17 de março de 2018. 